Health \& Medicine | Jan Czyzyk

\section{Could a serpin antibody help to treat type 1 diabetes?}

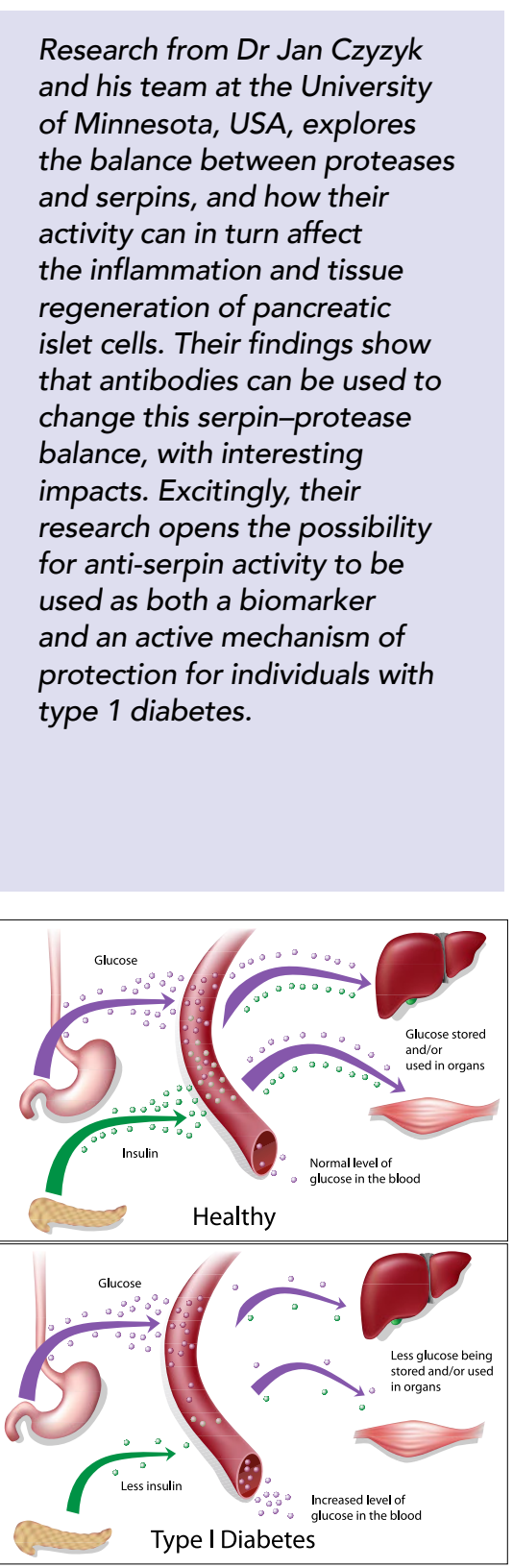

Type 1 diabetes is an autoimmune disease
where little or no insulin is produced by the where little or no insul
pancreatic islet cells.
Ithough it's sometimes
uncomfortable and painful
while we're experiencing it, inflammation is a vital process of the to harmful stimuli such as pathogens, damaged cells, or irritants. The goal of inflammation is to eliminate the cause of injury, clear away dead cells, and initite the process of tissue regeneration.

Tissue regeneration is the other side of the same process. It involves the renewal and restoration of biological tissues. All living things are capable of some form of tissue regeneration - although some than others. The regenerated tissue can me

The researchers" findings offer a practical approach to the therapy of inflammation and tissue regeneration in people with type 1 diabetes.

partially the same if the original tissue damage was too great.

the peptide bonds within proteins via broken by water). Conversely, serpins work to inhibit proteases, by permanently place where enzymes bind to moleculess.

team at the by Dr Jan Czyzzk ar explores this balance between

inflammation and tissue regeneration. They are specifically interested in the inflammation and tissue regeneration within your pancreas that produce the hormone insulfi, which regulates blood sugar levels). Their research suggests in humans could be ucluty detected biomarker and as an active me as a

The action of serpins is important: run rampant, high levels of protease activity can cause a lot of damage to the body. A low level of protease activity organisms, including humans. However, this doesn't mean proteases are 'bad' to inflammation is a vital process of the
human body. It's how the body responds species have a far greater capacity for it altering the shape of their active site (the of pancreatic islet cells (groups of cells art of life - they just need to be properly mediated.

PROTEASES AND TYPE 1 DIABETES Type 1 diabetes is an autoimmune produced by the pancreatic islet cells. Ou bodies use insulin to regulate the levels. of glucose in the bloodstream, so if the disease is left untreated, people with typ 1 diabetes are left with very high levels of sugar in their blood. They then suffer from symptoms such as weight loss, thirst, and tiredness. Diabetes needs to be manage throughout the rest of the person's life, either through regular insulin injections or via an insulin pump.

Czyzyk and his research team used type diabetes as a model of autoimmune disease in their studies. They successfuly denos the surface in inflammatory cells that accumula in pancreatic islets. Essentially, the proteases cut away the small proteins coating the surfaces of these cells.

By doing so, this impairs the function of the inflammatory cells and helps to lower inflammation within the pancreatic islets. In turn, Czyzyk's team showed that these changes can delay the clinical onset of type 1 diabetes in an animal model.

\section{NOTCH SIGNALLING PATHWAYS} More recent studies from Czyzyk's lab have shown a further interesting to to produce inu in the panat are able to produce insulin in the pancreas. Under called the 'Notch signalling pathway' is responsible for keeping stem cells in an undifferentiated state.

The Notch signalling pathway is present in most living animals. It involves the action of four receptors that play a major role in embryonic development as well as promoting neurogenesis (the process by which nervous system cells are produced from stem cells). Researchers believe that the Notch pathway also plays an important role in the development of the pancreas specifically the recruitment of endocrine that prose cels make up the glands that produce hormon
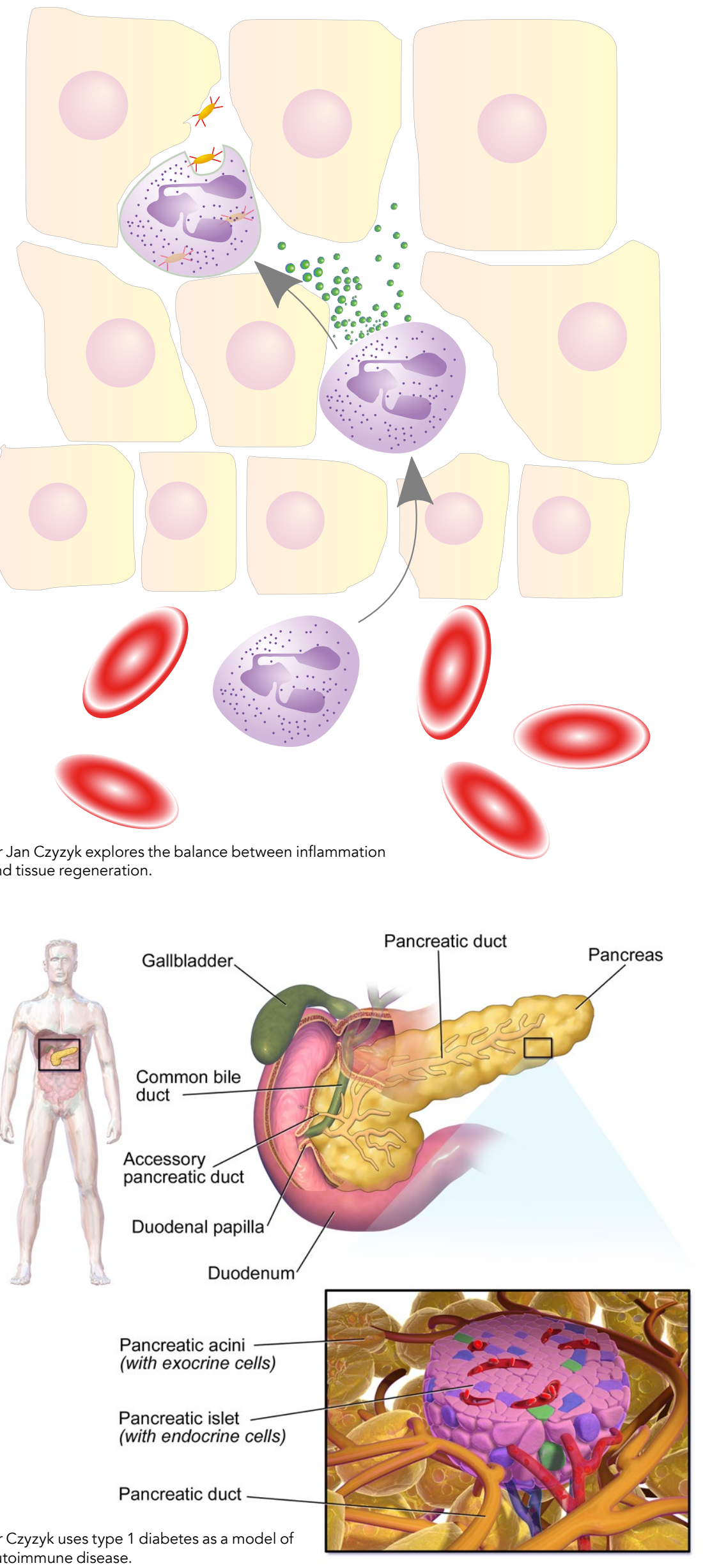


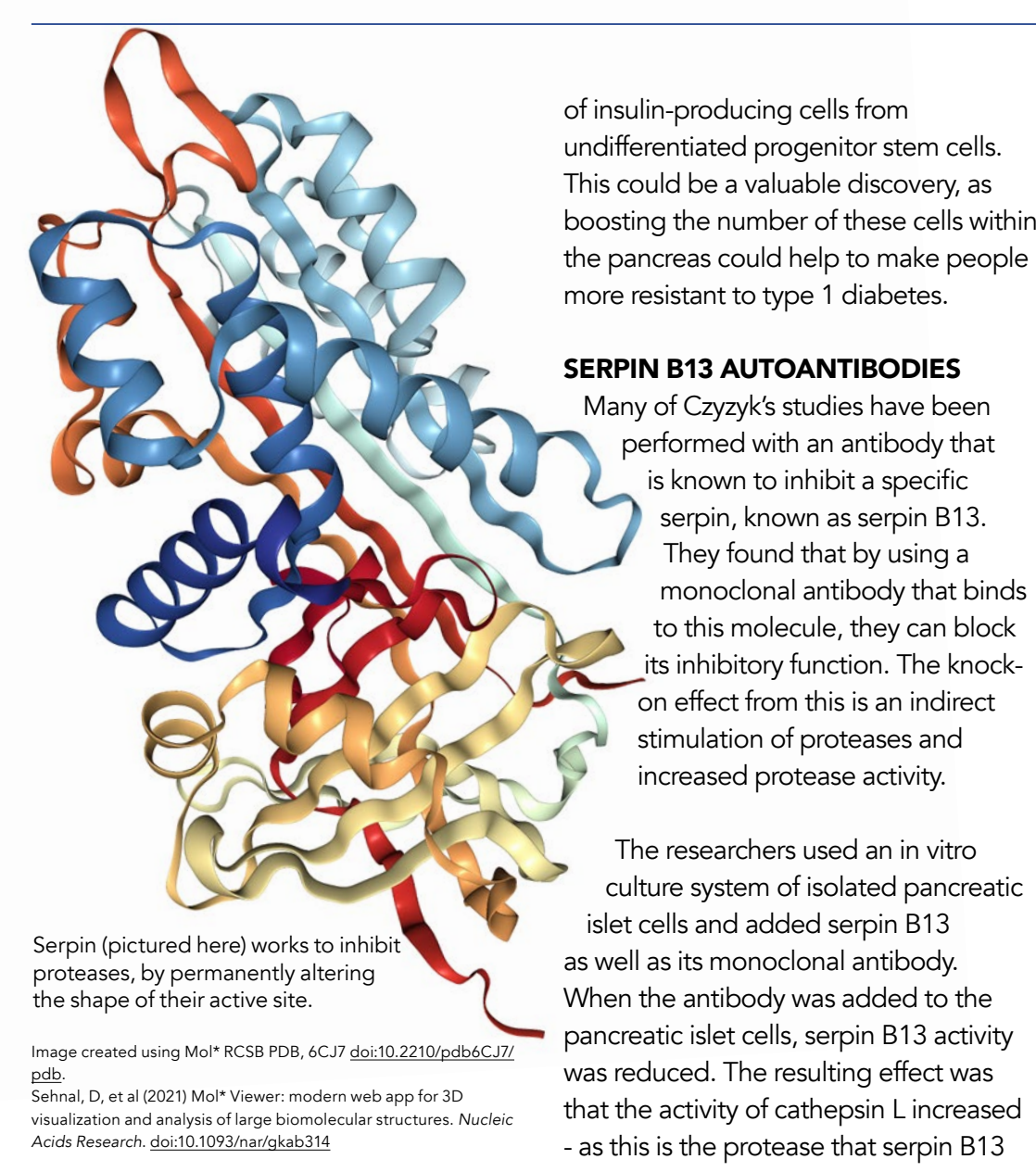

Children who are at high risk for type 1 diabetes and are positive for the autoantibody to serpin B13, do clinically better than children without the antibody.

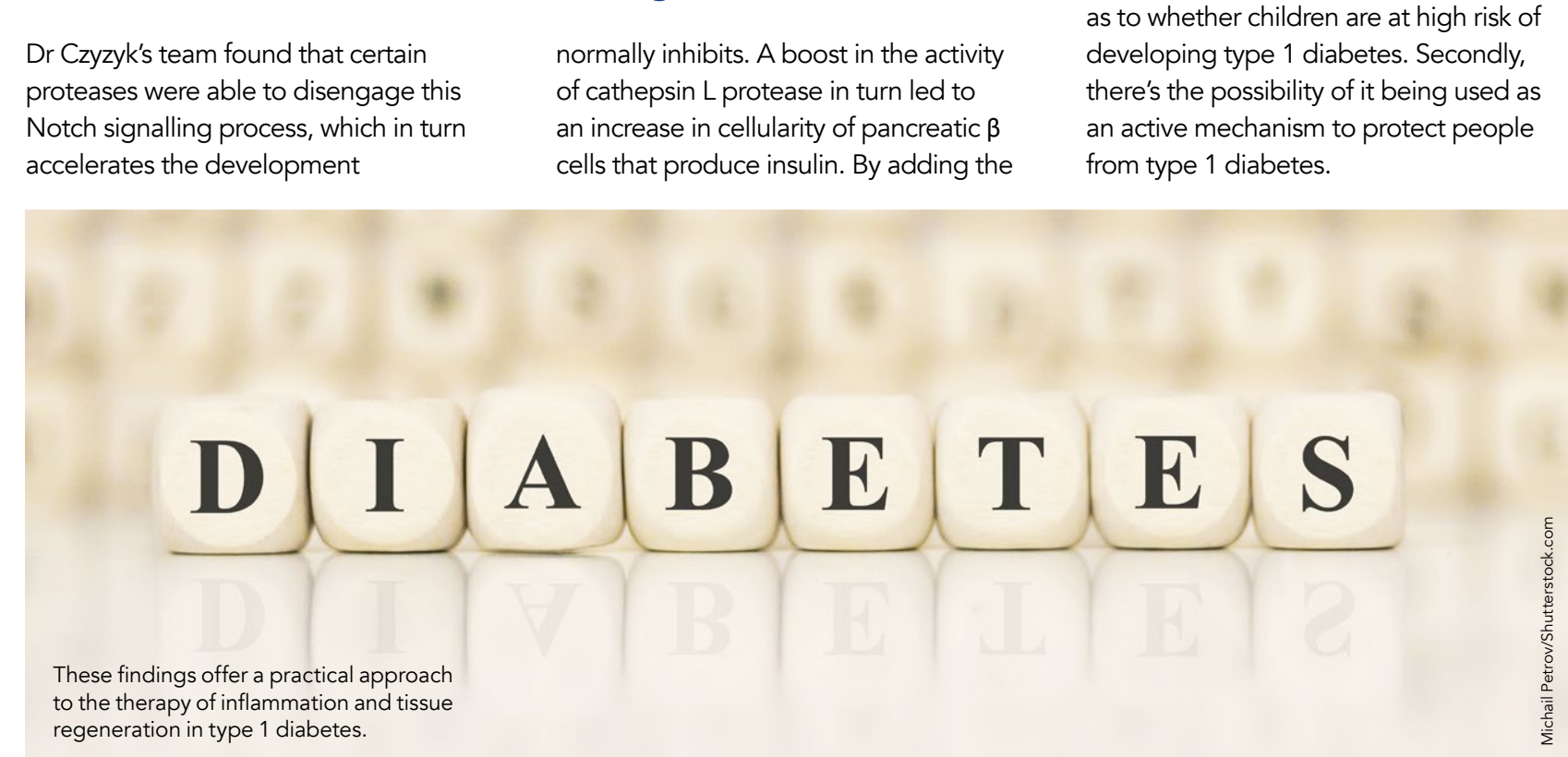

right dose of the antibody at the right the researchers' findings offer a practical approach to the therapy of inflammation and tissue regeneration in type 1 diabetes. In addition, the therapy could potentially be applied to other diseases that affect tissues with high expressions of serpin and Notch.

HELPING PEOPLE WITH DIABETES The most exciting part of Czyzyk's studies is the potential to translate the findings to help people at high risk of type 1 diabetes. The researchers found that children who are at high risk for type 1 diabetes, and are positive for the autoantibody to serpin B13, do better clinically than those without the antontibody tond to desop at a lower frequency.

A further study showed that anti-serpin in a similar way to a mouse monoclonal antibody to serpin B13. Interestingly, stimulate the development of endocrine progenitor cells in the mouse pancreas.
This suggests that the same process This suggests that
occurs in humans.

What could this mean for the future? Czyzyk's studies suggest that detectin anti-serpin activity within humans could be used in two ways. Firstly, it could be as tow a biomakn to offer doctors clues d abetes Secondly 西 moment, in lammation can be reduced B13 autoanthodies from humans function the mouse antibody to serpin B13 car

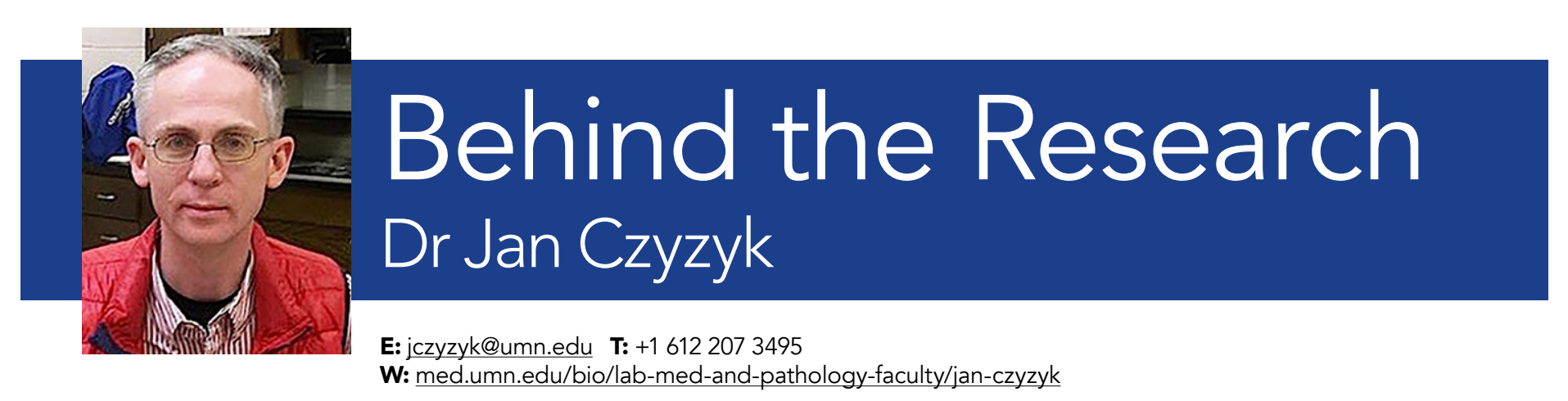

\section{Research Objectives}

Dr Czyzyk's research explores the balance between proteases and inhibitors of serpin proteases, and how they affect inflammation and tissue regeneration of pancreatic

\section{Detail}

Bio

Dr Jan Czyzyk did his MD at the Medical University of Warsaw in 1992. He moved to the University of North Carolina in 1993 where he was a postdoctoral research fellow. In 1996-1998, he completed his residency in anatomic pathology at Yale-New Haven Hospital, New Haven, CT, before carrying out a fellowship in renal pathology at the same institution. He is currently Associate Protessor at the Department of Laboratory Medicine and Pathology at the University of Minnesota

Funding

- JDRF

- NIDDK

- University of Rochester

- Yale University

- University of Minnesota

\section{Collaborators}

- Belgian Diabetes Registry

- Triallnet

- NIDDK Repository

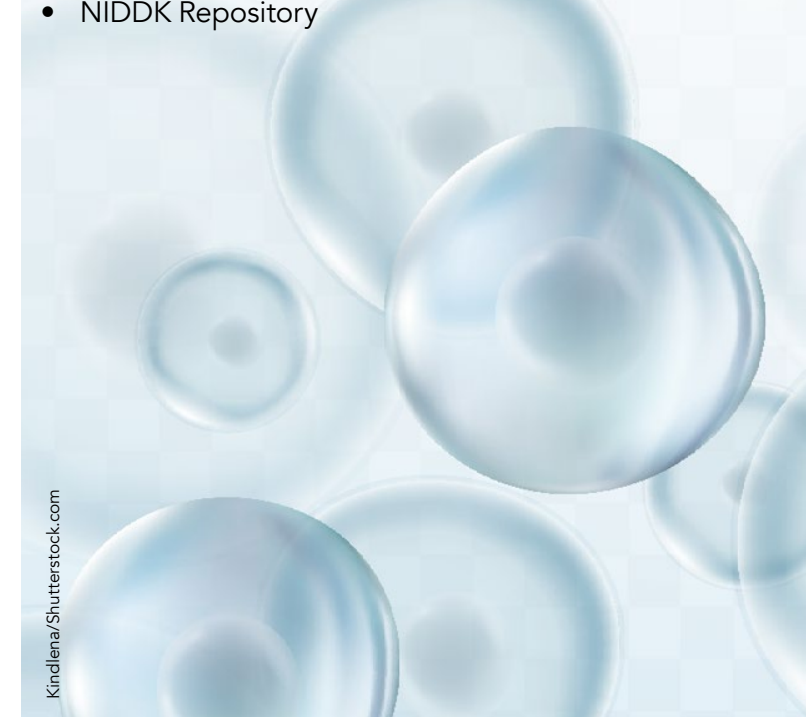

\section{References}

Czyzyk, J, et al, (2012) Enhanced anti-serpin antibody activity inhibits autoimmune inflammation in type 1 jimmunol.1200467

Baldzizhar, R, et al, (2013) Anti-serpin antibody-mediated regulation of proteases in autoimmune diabetes. $J$ Biol Chem 288, 1612-1619. doi.org/10.1074/jbc.M112.409664

Lo, C-W, et al, (2019) Cellular proliferation in mouse and human pancreatic islets is regulated by serpin B13 inhibition and downstream targeting of E-cadherin by cathepsin $L$.
Diabetologia 62:822-834, doi:10.1007/s00125-019-4834-0

Kryvalap, Y, et al, (2021) SerpinB13 antibodies promote $\beta$ cell development and resistance to type 1 diabetes. Sci abf1587

\section{Personal Response}

What do you believe to be the most exciting potential practical application of your research?

II The first exciting aspect of our discovery is that

therapy based on a monoclonal antibody to serpin B13, in addition to promoting tissue renewal, simultaneously impedes inflammation. This contrasts with traditional approaches to therapy in autoimmune diabetes that are based on attempts to separately inhibit autoimmune cells without influencing inflammation. The second exiting element of our discovery is based on the fact that inhibition of Notch mobilises stem cells. Our discovery of Notch extracellular cleavage by protease, which can be induced with an antibody to serpin B13, opens new opportunities for the therapy of diseases that affect tissues expressing serpin molecules. Diabetes may very well be just one of many conditions that could benefit from Notch-disengagement due to augmented II 